\title{
Antibiotic Susceptibility Profiles of Campylobacter coli Isolated from Poultry Farms in Lagos Nigeria - A Pilot Study
}

\author{
Oreva Ogbor ${ }^{1}$, Abraham Ajayi ${ }^{1}$, Andreas E. Zautner ${ }^{2 *} \dagger$ and Stella I. Smith ${ }^{3 *} \uparrow$ \\ ${ }^{1}$ Department of Microbiology, University of Lagos Akoka, Nigeria \\ ${ }^{2}$ Department of Medical Microbiology, University Medical Center Göttingen, Germany \\ ${ }^{3}$ Molecular Biology and Biotechnology Department, Nigerian Institute of Medical Research Lagos, Nigeria
}

Received: 26 March 2019; accepted: 09 April 2019

\begin{abstract}
Campylobacter jejuni and Campylobacter coli are among the leading causes of gastroenteritis in humans worldwide, particularly in Africa. Poultry remains a major source of Campylobacter species and a vector of transmission to humans.

This pilot study was aimed at isolating and determining the antibiotic susceptibility profiles of Campylobacter spp. from fresh poultry droppings collected from poultry farms in Lagos State, Nigeria. Susceptibility was assessed using the CLSI standards.

Standard microbiological methods were used in isolation, identification, and characterization of Campylobacter spp. Isolates were subjected to antibiotic susceptibility testing by the disk diffusion method.

Of the 150 poultry droppings analyzed, 8 (5.3\%) harbored Campylobacter spp. All isolates proved to be C. coli since they were all negative for the hip gene. A percentage of $100 \%$ showed resistance to nalidixic acid, chloramphenicol, cloxacillin, and streptomycin. While $87.5 \%$ were susceptible to amoxicillin and amoxicillin/clavulanic acid, $62.5 \%$ were susceptible to tetracycline. Surprisingly, $62.5 \%$ of $C$. coli had decreased (intermediate) susceptibility to erythromycin.

Although there was a low prevalence of $C$. coli from poultry in this study, the presence of antibiotic resistant strains circulating the food chain could result in treatment failures and difficulty in case management if involved in infections of humans.
\end{abstract}

Keywords: Keywords: Campylobacter coli, poultry, antibiotic susceptibility, Nigeria, Africa

\section{Introduction}

Campylobacter is one of the leading causes of gastroenteritis in humans worldwide, hence an important public health pathogen $[1,2]$. The symptoms of campylobacteriosis include watery and sometimes bloody diarrhea, fever, and abdominal pain [3]. Several weeks after acute campylobacteriosis post-infectious sequelae like the Guillain-Barré syndrome may follow [4]. Domestic animals, including farm animals and pets, are known primary reservoirs of Campylobacter [5, 6]. Campylobacter infections have been associated with the consumption of improperly cooked and cross-contaminated or inadequately processed foods, including poultry, beef, shellfish, unpasteurized milk, vegetables, and fruits [7]. Antibiotic resistance in Campylobacter is on the rise, especially in Africa. Smith et al. reported increased rates of streptomycin and cloxacillin resistance among Campylobacter spp. isolated from animals and humans in Nigeria [8]. However, there seem to be a paradigm shift as Campylobacter species are now multiple resistant. This means that the isolates are unsusceptible to a wider range of antibiotics; in particular, the high level resistance to tetracycline and fluoroquinolones is of importance [9-12].

*Authors for correspondence: Universitätsmedizin Göttingen, Institut für Medizinische Mikrobiologie, Kreuzbergring 57, D-37075 Göttingen, Germany; Phone: +49-551-398549; Fax: +49-551-395861, E-mail: azautne@gwdg.de. Molecular Biology and Biotechnology Department,Nigerian Institute of Medical Research Yaba, Lagos Nigeria; Phone: +2348037058989; E-mail: stellaismith@yahoo.com.

$\dagger$ Joint corresponding author and both authors contributed equally to this work.
Since poultry are largely consumed food animals in Nigeria, and the prevalence of Campylobacter in Nigerian poultry was rated high [2, 13-15], this study therefore seeks to classify, evaluate the isolation rate, and the antibiotic susceptibility pattern of Campylobacter spp. isolated from poultry in Lagos Nigeria based on a broader test panel of 13 antimicrobial substances. In particular, antibiotic resistance may cause therapy failure in complicated campylobacteriosis, especially in children and immunosuppressed patients.

\section{Materials and Methods}

Sample Collection. Fresh poultry droppings were randomly collected immediately after defecation from 116 (77.3\%) chickens and $34(22.7 \%)$ guinea fowls in various farms in Lagos State, Nigeria. Sterile spoons attached to universal bottles were used to collect the fecal samples and streaked immediately on site onto $5 \%$ sheep blood agar plates containing Campylobacter supplement (Oxoid, Butzler SR85) [13]. Inoculated plates were transported to the laboratory in gas jars using microaerophilic atmosphere generating sachets (CampyGen Oxoid CN35A, UK) to produce conditions suitable for the growth of Campylobacter.

Isolation of Campylobacter. Isolation of Campylobacter was done according to the method of Zhao et al., with slight modifications [16]. The blood agar plates inoculated with fecal samples were incubated at $42{ }^{\circ} \mathrm{C}$ for $48 \mathrm{~h}$. Suspected colonies with phenotypic characteristics of Campylobacter

This is an open-access article distributed under the terms of the Creative Commons Attribution-NonCommercial 4.0 International License (https://creativecommons.org/licenses/by-nc/4.0/), which permits unrestricted use, distribution, and reproduction in any medium for non-commercial purposes, provided the original author and source are credited, a link to the CC License is provided, and changes - if any - are indicated. 
were subcultured onto blood agar plates and incubated for $24 \mathrm{~h}$ at $42{ }^{\circ} \mathrm{C}$ in a candle jar under microaerophilic conditions. Suspected colonies were Gram-stained and subjected to biochemical characterization using Campy APIsystems (bioMérieux, Marcy-l'Étoile, France).

Antibiotic Susceptibility Testing. Isolates were subjected to antimicrobial susceptibility testing using the disk diffusion method as described by Olabode et al. [17]. Thirteen antibiotics (Oxoid, Hampshire, UK) were used including amoxicillin/clavulanic acid $(30 \mu \mathrm{g})$, amoxicillin $(25 \mu \mathrm{g})$, tetracycline $(25 \mu \mathrm{g})$, erythromycin $(5 \mu \mathrm{g})$, nitrofurantoin (200 $\mu \mathrm{g})$, gentamicin $(10 \mu \mathrm{g})$, ofloxacin $(5 \mu \mathrm{g})$, clarithromycin $(10 \mu \mathrm{g})$, cotrimoxazole $(25 \mu \mathrm{g})$, nalidixic acid $(30 \mu \mathrm{g})$, chloramphenicol $(10 \mu \mathrm{g})$, cloxacillin $(5 \mu \mathrm{g})$, and streptomycin $(10 \mu \mathrm{g})$.

The antibiotic-impregnated disks were placed on the inoculated blood agar plates using sterile forceps and incubated at $42{ }^{\circ} \mathrm{C}$ for $48 \mathrm{~h}$. The clear zones of inhibition were measured to the nearest millimeter using a transparent millimeter ruler and analyzed as described by Clinical and Laboratory Standard Institute [18].

Polymerase Chain Reaction (PCR) for Suspect Campylobacter Spp. DNA extraction of Campylobacter spp. was done as described by Samosornsuk et al. [19]. The hippurate hydrolase (hip) gene was detected by PCR using the primers: Forward 5'-GAA-GAG-GGT-TTG-GGT-GGT-G-3' and Reverse 5'-AGC-TAG-CTT-CGC-ATA-ATA-ACT-TG-3'. A $25-\mu \mathrm{L}$ reaction was used, which contained $5-\mu \mathrm{L}$ template DNA and $0.2 \mu \mathrm{M}$ of each primer [20]. PCR was carried out in a thermocycler (Eppendorf AG, Hamburg, Germany) with cycling parameter as follows: denaturation at $94{ }^{\circ} \mathrm{C}$ for $1 \mathrm{~min}$, annealing at $66{ }^{\circ} \mathrm{C}$ for $1 \mathrm{~min}$, and extension at $72{ }^{\circ} \mathrm{C}$ for $1 \mathrm{~min}$. PCR amplicons were electrophoretically separated in $1 \%$ agarose gels (Sigma type II, medium EEO), stained with ethidium bromide and visualized under ultraviolet (UV) light.

Ethical Approval. The study did not require an ethical approval, since faecal samples were collected after the birds defecated. Hence there was no direct contact with the birds. However all organizational and institutional ethics were strictly adhered to.

\section{Results}

Campylobacter spp. were isolated from $8(5.3 \%)$ of the total 150 fresh poultry droppings analyzed. Isolates were obtained from $6 / 8(75 \%)$ of chicken and $2 / 8(25 \%)$ of guinea fowl droppings. All 8 Campylobacter isolates were tested negative for the hip gene and thus classified as Campylobacter coli with a prevalence of $5.3 \%(8 / 150)$

Table 1. Antibiotic susceptibility pattern of Campylobacter coli to test antibiotics

\begin{tabular}{lccc}
\hline Antibiotics & $\begin{array}{c}\text { Sensitive } \\
(\%)\end{array}$ & $\begin{array}{c}\text { Intermediate } \\
(\%)\end{array}$ & $\begin{array}{c}\text { Resistant } \\
(\%)\end{array}$ \\
\hline Amoxicillin/clavulanic acid & $7 / 8(87.5)$ & $1 / 8(12.5)$ & $0 / 8(0.0)$ \\
(AUG) & $7 / 8(87.5)$ & $1 / 8(12.5)$ & $0 / 8(0.0)$ \\
Amoxicillin (AMX) & $5 / 8(62.5)$ & $1 / 8(12.5)$ & $2 / 8(25.0)$ \\
Tetracycline (TET) & $1 / 8(12.5)$ & $5 / 8(62.5)$ & $2 / 8(25.0)$ \\
Erythromycin (ERY) & $3 / 8(37.5)$ & $1 / 8(12.5)$ & $4 / 8(50.0)$ \\
Nitrofurantoin (NIT) & $2 / 8(25.0)$ & $0 / 8(0.0)$ & $6 / 8(75.0)$ \\
Gentamicin (GEN) & $2 / 8(25.0)$ & $1 / 8(12.5)$ & $5 / 8(62.5)$ \\
Ofloxacin (OFL) & $1 / 8(12.5)$ & $0 / 8(0.0)$ & $7 / 8(87.5)$ \\
Clarithromycin (CLR) & $0 / 8(0.0)$ & $1 / 8(12.5)$ & $7 / 8(87.5)$ \\
Cotrimoxazole (COT) & $0 / 8(0.0)$ & $0 / 8(0.0)$ & $8 / 8(100)$ \\
Nalidixic acid (NAL) & $0 / 8(0.0)$ & $0 / 8(0.0)$ & $8 / 8(100)$ \\
Chloramphenicol (CHL) & $0 / 8(0.0)$ & $0 / 8(0.0)$ & $8 / 8(100)$ \\
Cloxacillin (OXL) & $0 / 8(0.0)$ & $0 / 8(0.0)$ & $8 / 8(100)$ \\
Streptomycin (STR) & & &
\end{tabular}

All C. coli isolates were resistant to one or more of the antibiotics tested as shown in Table 1. A vast majority of isolates were resistant to nitrofurantoin $4 / 8(50.0 \%)$, gentamycin $6 /$ $8(75.0 \%)$, ofloxacin $5 / 8(62.5 \%)$, clarithromycin $7 / 8(87.5 \%)$, cotrimoxazole $7 / 8(87.5 \%)$, nalidixic acid $8 / 8(100 \%)$, chloramphenicol 8/8 (100\%), cloxacillin 8/8 (100\%), and streptomycin $8 / 8(100 \%)$. Five $(62.5 \%)$ of the isolates showed decreased susceptibility (i.e., were intermediate tested) to erythromycin. Seven $(87.5 \%)$ of the isolates showed susceptibility to amoxicillin/clavulanic acid and amoxicillin, while 5/ $8(62.5 \%)$ were tested susceptible to tetracycline.

\section{Discussion}

Poultry has been reported to be a major reservoir of Campylobacter spp. with high levels of up to $9.0 \log _{10} \mathrm{CFU} / \mathrm{g}$ (colony-forming units per gram) in the gut and cecal content of colonized birds which are majorly asymptomatic, hence promoting transmission among the flock [21]. The 5.3\% prevalence of Campylobacter coli isolated from poultry droppings in this study is relatively low compared to the $47.3 \%$ and $20 \%$ in 1988 and 2005, respectively, reported in the same Nigerian state [13]. Similarly studies conducted in the northern part of Nigeria, i.e., in Sokoto State, showed a prevalence of $30 \%$ and $77.6 \%[7,22]$. The low isolation rate may be due to the indiscriminate use of antibiotics by poultry farmers in Nigeria as observed by Amaechi et al. in another study, which showed that erythromycin and tetracycline were the commonly used antibiotics by farmers in Nigeria in recent times [23]. Viable but non-culturable (VBNC) state of isolates in the bird feces, which is a survival response to stress, could be another reason for the low isolation rate $[13,24]$.

Globally antimicrobial resistance of bacterial isolates of food, animal and human origin is on the rise [1, 25]. Campylobacter isolates demonstrated varied antimicrobial susceptibility. Approximately $85.7 \%$ showed sensitivity to amoxicillin/clavulanic acid and amoxicillin, while 57.14\% showed sensitivity to tetracycline. However, all the isolates were resistant to gentamicin, nalidixic acid, cloxacillin, chloramphenicol, and streptomycin and demonstrated decreased sensitivity to erythromycin. This is in line with the studies of Biswas et al., which reported a high level of resistance to nalidixic acid and susceptibility to erythromycin [26]. Additionally, Elhadidy et al. reported $40.7 \%$ multidrug-resistant $C$. coli isolates cultured from broiler carcasses and feces of diarrheal patients in Belgium [27]. Similarly, Wei and Kang reported the resistance profile of 8 Campylobacter isolates from avian sources that were resistant to fluoroquinolones, ampicillin, tetracycline, and macrolides [28]. The persistence of antibiotic resistant Campylobacter strains in the food chain remains a public health risk.

The limitations of this study are the geographical coverage area, the number of samples considered, and, consecutively, the number of bacterial isolates and microbial species tested. These shortcomings will be addressed in the main study based on this pilot study in the following way: sampling will take place in 20-30 households from each of 6 areas in Nigeria, namely, Northwest, Northcentral, Northeast, Southwest, Southcentral, and Southeast Nigeria. A much larger number of samples will be targeted as cross-sectional studies will be conducted to detect and isolate Campylobacter and Arcobacter from feces and/or cloacal/anal swabs from domesticated and neighboring wild animals, as well as water reservoirs and food if present. Cross-sectional and case control studies will be used for humans with diarrhea and those without diarrhea as well as malnourished and non-malnourished children. In addition to $C$. coli, all other microbial species of the genera 
Campylobacter and Arcobacter will be included in the susceptibility testing.

However being a pilot study, it has provided a basis for design and execution of a larger study.

\section{Conclusion}

Poultry being a major source of animal protein to man remain one major vector for the transmission of Campylobacter and, in particular, antibiotic resistant strains. Although there was a low prevalence of $C$. coli isolated from chicken and guinea fowl in this study, the presence of strains with resistance to multiple antibiotics was significant. Such multidrugresistant strains circulating the food chain could result in treatment failures and difficulty in case management if involved in human infection. Therefore, an extensive study is advocated that would provide data needed to inform policy for surveillance and monitoring of campylobacteriosis.

\section{Funding Sources}

No financial support was received for this study.

\section{Authors' Contributions}

S.I.S. conceptualized and supervised the study, O.O. collected the samples and carried out laboratory work, A.A. and A.E.Z. analyzed the results and drafted the manuscript, and S. I.S. and A.E.Z. reviewed and edited the manuscript. All authors read and approved the final manuscript.

\section{Conflicts of Interest}

The authors declare no conflict of interest.

Acknowledgements. This paper was funded by the Open Access support program of the Deutsche Forschungsgemeinschaft and the publication fund of the Georg August Universität Göttingen.

\section{References}

1. Komba EVG, Mdegela RH, Msoffe PLM, Matowo DE, Maro MJ. Occurrence, species distribution and antimicrobial resistance of thermophilic Campylobacter isolates from farm and laboratory animals in Morogoro. Tanzania. Vet World. 2014;7:559-65.

2. Ngulukun S, Oboegbulem S, Klein G. Multilocus sequence typing of Campylobacter jejuni and Campylobacter coli isolates from poultry, cattle and humans in Nigeria. J Appl Microbiol. 2016;121:561-8.

3. Dasti JI, Tareen AM, Lugert R, Zautner AE, Gross U. Campylobacter jejuni: a brief overview on pathogenicity-associated factors and diseasemediating mechanisms. Int J Med Microbiol. 2010;300:205-11.

4. Zautner AE, Johann C, Strubel A, Busse C, Tareen AM, Masanta WO, et al. Seroprevalence of campylobacteriosis and relevant post-infectious sequelae. Eur J Clin Microbiol Infect Dis. 2014;33:1019-27.

5. Coker AO, Isokpehi RD, Thomas BN, Fagbenro-Beyioku AF, Omilabu SA. Zoonotic infections in Nigeria: overview from a medical perspective. Acta Trop. 2000;76:59-63.
6. Salihu MD, Magaji AA, Abdulkadir JU, Kolawale A. Survey of thermophilic Campylobacter species in cats and dogs in north-western Nigeria. Vet Ital. 2010;46:425-30.

7. Nwankwo IO, Faleke OO, Salihu MD, Magaji AA, Musa U, Garba J. Epidemiology of Campylobacter species in poultry and humans in the four agricultural zones of Sokoto State. Nigeria. J Public Health Epidemiol. 2016;8:184-90

8. Smith SI, Sansa TI, Coker AO. Antibiotic susceptibility patterns and beta-lactamase production of animal and human isolates of Campylobacter in Lagos, Nigeria. Z Naturforschung C. J Biosci. 1999;54:583-6.

9. Uaboi-Egbenni PO, Bessong PO, Samie S, Obi CL. Prevalence and antimicrobial susceptibility profiles of Campylobacter jejuni and coli isolated from diarrheic and non-diarrheic goat faeces in Venda region, South Africa. Afr J Biotechnol. 2011;10:14116-24.

10. World Health Organization (WHO). The global view of campylobacteriosis. Utrecht: Netherlands; 2013.

11. Karikari AB, Obiri-Danso K, Frimpong EH, Krogfelt KA. Antibiotic Resistance of Campylobacter Recovered from Faeces and Carcasses of Healthy Livestock. BioMed Res Int. 2017;2017:4091856.

12. Komba EV. Human and Animal Thermophilic Campylobacter infections in East African countries: Epidemiology and Antibiogram. Biomed $J$ Sci Tech Res. 2017;1.

13. Aboaba OO, Smith SI. Occurrence of Campylobacter spp. in Poultry farms in Lagos State of Nigeria. J Env Biol. 2005;26:403-8.

14. Balogu TV, Nwaugo VO, Onyeagba RA. Persistence and Biofilm Assessment of Campylobacter jejuni in Poultry Abattoir. Niger Food J. 2014;32:54-61

15. Braide W, Adeleye SA, Ohanusi I, Ibegbulem CR, Mike-Anaosike EE, Madu LC. Incidence of Campylobacter Species in Poultry Products and Beef Sold in Owerri, Imo State. Nigeria. 2017;10:147-55.

16. Zhao C, Ge B, De Villena J, Sudler R, Yeh E, Zhao S, et al. Prevalence of Campylobacter spp., Escherichia coli, and Salmonella serovars in retail chicken, turkey, pork, and beef from the Greater Washington, D.C., area. Appl Environ Microbiol. 2001;67:5431-6.

17. Olabode HOK, Ogbole SM, Ifeanyi GRO, Ugbaja HOO. Isolation and Antibiotic Susceptibility of Campylobacter Species from Cattle Offals in Gwagwalada Abattoir, Abuja-FCT Nigeria. Int J Curr Microbiol Appl Sci. 2017;6:324-33.

18. Clinical and Laboratory Standards Institute (CLSI). Performance Standards for Antimicrobial Susceptibility Testing 26th ed. CLSI Supplement M100S. 2016

19. Samosornsuk W, Asakura M, Yoshida E, Taguchi T, Eampokalap B, Chaicumpa W, et al. Isolation and Characterization of Campylobacter Strains from Diarrheal Patients in Central and Suburban Bangkok. Thailand. Jpn J Infect Dis. 2015;68:209-15.

20. Ramadan H, Jackson C, Hinton $\mathrm{Jr}$ A. Screening and Rapid Identification of Campylobacter Spp. DNA by FlaA PCR Based Method on Chicken and Human Fecal Samples in Egypt. Int J Poult Sci. 2015;14:252-6.

21. Obeng AS, Rickard H, Sexton M, Pang Y, Peng H, Barton M. Antimicrobial susceptibilities and resistance genes in Campylobacter strains isolated from poultry and pigs in Australia. J Appl Microbiol. 2012;113:294-307.

22. Salihu MD, Junaidu AU, Oboegbulem SI, Egwu GO, Magaji AA, Abubakar MB, et al. Prevalence of Campylobacter spp. in Nigerian Indigenous Chicken in Sokoto State Northwestern Nigeria. Internet J Vet Med. 2008;7.

23. Amaechi N. A Survey on Antibiotic usage in Pigs and Poultry Birds in Abia State, Nigeria. Glob J Med Res. 2014;14:10-17.

24. Bhavsar SP, Kapadnis BP. Virulence factors of Campylobacter. Internet $J$ Microbiol. 2006;3:1-7.

25. Thorsteinsdottir TR, Kristinsson KG, Fridriksdottir V, Gunnarsson E. Antimicrobial resistance of Campylobacter spp. isolated from broiler flocks in Iceland 2001-2005. Microb Drug Resist Larchmt N. 2008;14:49-53.

26. Biswas D, Hannon SJ, Townsend HGG, Potter A, Allan BJ.: Genes coding for virulence determinants of Campylobacter jejuni in human clinical and cattle isolates from Alberta, Canada, and their potential role in colonization of poultry. Int Microbiol Off J Span Soc Microbiol. 2011;14:25-32.

27. Elhadidy M, Miller WG, Arguello H, Álvarez-Ordóñez A, Dierick K, Botteldoorn N. Molecular epidemiology and antimicrobial resistance mechanisms of Campylobacter coli from diarrhoeal patients and broiler carcasses in Belgium. Transbound Emerg Dis. 2019;66:463-75.

28. Wei B, Kang M. In vitro activity of fosfomycin against Campylobacter isolates from poultry and wild birds. PloS One. 2018;13:e0200853. 